\title{
The Potential Value of Adipose Tissue-Derived((rAT)) Mesenchymal Stem Cells (MSCs)
}

\author{
Huajiang DONG ${ }^{1,2^{*}}$, Gang $\mathrm{LI}^{1,2}$, Hong-Jun DING ${ }^{*}$, Yuechen $\mathrm{LUO}^{3}$, Mingliang $\mathrm{ZHAO}^{4}$, Ling $\mathrm{LIN}^{1,2}$ \\ ${ }^{1}$ State Key Laboratory of Precision Measurement Technology and Instruments, Tianjin University, Tianjin, China \\ ${ }^{2}$ Logistics University of Chinese People's Armed Police Forces, Tianjin, China \\ ${ }^{3}$ State Key Laboratory of Experimental Hematology, Institute of Hematology and Blood Disease Hospital, Chinese Academy of Medical Sciences \\ and Peking Union Medical College, Tianjin, China \\ ${ }^{4}$ Tianjin Key Laboratory of Neurotrauma Repair; Neurological Hospital, Affiliated Hospital of Logistics University of Chinese People's Armed Police \\ Forces, Tianjin, China \\ *Drs. DONG and DING are equally contributed to this work.
}

To the Editor;

$\mathrm{T}$ The recent article on the effects of rat adipose tissuederived ( $\mathrm{rAT}$ ) mesenchymal stem cells (MSCs) transplantation during the acute and subacute phases following spinal cord injury (SCl) in Turkish Neurosurgery is very interesting (1). Aras et al. reported that "the effectiveness of the treatment strategies, i.e., injections during the acute and subacute phases, was compared. Adipose tissue-derived stem cells have been shown to differentiate into oligodendrocytes, which participate in the functional recovery of $\mathrm{SCl}$ in rat models" and "the transplantation of MSCs derived from different tissues improved the locomotor recovery following $\mathrm{SCl}$, and the capacity of rAT-MSCs to differentiate into the oligodendrocyte lineage improved the functional recovery" (1).

We would like to share our ideas and experience on this topic. The first issue is whether the injection of MSCs in acute phases of $\mathrm{SCl}$ is suitable. We think allogeneic MSCs transplantation in the acute phase may have more severe cell rejection, affecting the survival rate of transplanted MSCs. The second issue is how long the rAT-MSCs can differentiate into injured cells to replace damaged tissue in $\mathrm{SCl}$ and whether the therapeutic effect of rAT-MSCs is due to cell replacement or a "by-stander effect" or both? On the one hand, the original intent of stem cell transplantation in the treatment of clinical diseases has been cell replacement therapy; namely, MSCs can differentiate into injured cells to replace damaged tissue owing to the cells' capacities for proliferation and differentiation. Certain experiments have shown that the therapeutic effects of the
MSCs were verified after MSC transplantation $(2,3,4)$; on the other hand, MSCs secrete a variety of cytokines and growth factors through paracrine or autocrine mechanisms, including vascular endothelial growth factor (VEGF), basic fibroblast growth factor (BFGF), hepatocyte growth factor (HGF), hypoxia-inducible factor-1a (HIF-1a) etc., that induce microvascular generation, stimulate peripheral mature endothelial cells proliferation and migration, and improve the micro-environment of ischemic tissue to participate in angiogenesis (5), all of which provide benefits to the injured tissue. The third issue is the safety of rAT-MSCs. The safety issue would be questioned by both doctors and patients in the future when clinical trials are conducted. If the rAT-MSCs for SCl therapy are used unsafely or improperly, they might result in some side effects. Irregular MSC therapy is associated with potential danger, including tumor growth or cancer. Therefore, it is necessary to evaluate the systematic safety of rAT-MSCs before treatment, for example: how many rAT-MSCs, which is the optimal path, and the specific mechanism of rAT-MSCs as cell replacement or "by-stander effect". rAT-MSCs would be potential "golden seed cells" for many diseases if the questions above can be solved, and would benefit the patients who need treatment with rAT-MSCs in the future.

\section{ACKNOWLEDGEMENTS}

This work was supported by the National Natural Science Foundation of China (81401295), the Tianjin Research Program of Application Foundation and Advanced Technology 
(15JCQNJC45200 and 16JCYBJC27600), the PUMC Youth Fund and the Fundamental Research Funds for the Central Universities (3332015126).

\section{- REFERENCES}

1. Aras Y, Sabanci PA, Kabatas S, Duruksu G, Subasi C, Erguven M, Karaoz E: The effects of adipose tissue-derived mesenchymal stem cell transplantation during the acute and subacute phases following spinal cord injury. Turk Neurosurg 26(1):127-139, 2016

2. Dong H, Shang C, Li G, Luo Y, Yang Y, Lin L, Zhao M: Differential protein expression in an acute disseminated myelitis patient after treatment with umbilical cord mesenchymal stem cells. Int J Clin Exp Med 10:7213-7219, 2017
3. Huang CC, Chen DY, Wei HJ, Lin KJ, Wu CT, Lee TY, Hu HY, Hwang SM, Chang Y, Sung HW: Hypoxia-induced therapeutic neovascularization in a mouse model of an ischemic limb using cell aggregates composed of HUVECs and cbMSCs. Biomaterials 34:9441-9450, 2013

4. Le Blanc K, Frassoni F, Ball L, Locatelli F, Roelofs H, Lewis I, Lanino E, Sundberg B, Bernardo ME, Remberger M, Dini G, Egeler RM, Bacigalupo A, Fibbe W, Ringdén O; Developmental Committee of the European Group for Blood and Marrow Transplantation: Mesenchymal stem cells for treatment of steroid-resistant, severe, acute graft-versus-host disease: $A$ phase II study. Lancet 371:1579-1586, 2008

5. Zhang B, Wu X, Zhang X, Sun Y, Yan Y, Shi H, Zhu Y, Wu L, Pan Z, Zhu W, Qian H, Xu W: Human umbilical cord mesenchymal stem cell exosomes enhance angiogenesis through the Wnt4/ beta-catenin pathway. Stem Cells Transl Med 4:513-522, 2015 